\title{
Clever House Made by Using a New Kind of the Nanocomposites
}

\author{
Andrey Ponomarev and Timur Plavnik \\ St. Petersburg State Polytechnical University, Saint Petersburg 195251, Russia \\ Correspondence should be addressed to Andrey Ponomarev; 9293522@gmail.com
}

Received 29 November 2015; Revised 19 May 2016; Accepted 9 June 2016

Academic Editor: Rafik Belarbi

Copyright (C) 2016 A. Ponomarev and T. Plavnik. This is an open access article distributed under the Creative Commons Attribution License, which permits unrestricted use, distribution, and reproduction in any medium, provided the original work is properly cited.

\begin{abstract}
The materials of this paper concern a new nanocomposites perspective for construction. The development of research in the field of production and application of nanocomposite materials has made it possible to develop building materials, having high exploitation characteristics. One of such materials is a polydisperse armed water soluble epoxy composite coat, named "EpoxyPAN." This material consists of the water soluble epoxy resin filled by the high strength inorganic fillers and the unique nanocarbon particles, astralenes and nanoporous microfiber. It was found that EpoxyPAN is possible to be used as effective water protection coating and simultaneously as effective electromagnetic waves absorber. The physical and exploitation properties of this nanocomposite and the possible ways of its applications for the Clever House constructions are also described in this paper.
\end{abstract}

\section{Introduction}

The term "Clever House" is not an exact concept; generally it describes a house, which contains electronic system for monitoring and managing the parameters of the living area and the infrastructure systems. However, due to the large amount of the electronic systems such house may become invalid and even dangerous for the inhabitants.

The most important parameters of the living area are

(i) comfortable atmosphere inside the house;

(ii) electromagnetic comfort, which means the minimal level of electromagnetic "smog" inside the house at wide range of frequencies;

(iii) the possibility of constant monitoring of the status of framing for the mitigation of the consequences of natural and technogenic accidents.

Almost all of these functions may be executed by electronic systems, but these systems can be damaged by wide range of actions.

Such tasks can be solved by the new kinds of the composite materials, based on the carbon nanoparticles (astralenes [1] and carbon nanoporous microfiber [2]), used as the part of the house constructions. These materials are represented by high performance composite nanoconcrete [3] and new kinds of polymer nanocomposites and have nonlinear properties in the wide range of the frequencies of the electromagnetic waves [4], what makes it possible to realize the electromagnetic waves limiting phenomena for the wide range of irradiation.

Also, the epoxy polymers with some carbon nanoparticles additive inside are able to become the metamaterial at the frequency to $1 \mathrm{GHz}$. These phenomena have been found to create a possibility for developing sensitive sensors for the monitoring of the value of the pressure and temperature inside the main house framing.

In order to prevent heat losses through wet walls of the house, the new nanocomposite multifunctional coating "EpoxyPAN" [TC 23 1253-053-91957749-2011] was developed.

Possible and realized ways to apply nanocomposites and advantages that these ways give are discussed in this paper.

\section{Materials and Methods}

2.1. Nanoparticles and Nanocomposites. Several dozens of carbon nanoparticles types are known now. But new kinds of carbon clusters are being researched and developed continuously [1-3]. And in each case their properties and behavior into the different media are being researched [4]. First and the most complete works, concerning the phenomenon of the influence on the properties of the cement concretes, caused by carbon nanotubes and astralenes, were [5, 6]. Due to this idea, the large number of different manufacturing methods $[7,8]$ 
and special concretes were developed [9]. The best example of such concrete is the light nanoconcrete with high pressure strength, grate mobility [10], and high level of waterproof. Last property can be useful to the buildings with high value of energy efficiency.

In this case, the heat transfer coefficient may be less than 0.5 . However, it is not enough for supplying the atmosphere comfort inside the house because of the possibility of the great changes in the external humidity. For the wet concrete walls the value of the heat transfer coefficient may be increased by several times. High quality of moisture isolation is one of the main requirements for the house comfort. And this task can be executed by application of the high waterproof building materials or electronic controllers and regulators of the humidity inside the house. Further we will discuss the new composite materials for moisture insulating with a high value of lifetime.

Also each urban region is treated by the electromagnetic waves from radars, mobile phones, and so forth. It can cause negative effects on human health. The best way to avoid these negative factors is to use an effective electromagnetic wave absorber, as one of the materials for the enclosing parts. But there are a large number of frequencies for different electromagnetic waves irradiators. For this reason it is important to use several types of electromagnetic waves absorbers simultaneously. But this way is rather expansive. New kinds of nanocomposites can provide proper protection from electromagnetic waves for more appropriate price.

People usually do not bother about the risks of natural or technogenic catastrophes (earthquake, tornado, etc.) in their regions. Such accidents take place rarely. Governments and engineers pay attention now to the task of risk analysis and methods of the mitigation of the consequences of such accidents [11, 12]. The main possibilities of mitigation of the consequences of catastrophes are the increasing quality of the civil engineering and application of the simple and reliable methods of monitoring the building state in a time.

\subsection{EpoxyPAN Technology as a High Quality Moisture Insu-} lating and Heat Saving Method in the House Construction and the Examples of Its Application. There are a large number of waterproof coatings for the concrete and other building materials [13, 14]. All these coatings have a lifetime from 3 to 7 years. Such small lifetime of the polymer coating is caused by the heat-oxidation destruction and photo- and radiationoxidation destruction. The best way to decrease the value of this phenomenon is to use the special stabilizers inside the polymer, which will put the brakes on these reactions. The best stabilizers are the aromatic combines with numerous half-free electrons, especially if they have more than $10^{6}$ carbon atoms.

Astralenes are the carbon particles with numerous halffree electrons (more then $10^{7}$ ) and a large number of double bonds between the carbon atoms. These particles can perform proper stabilization process.

Another problem of polymer coating technology is the level of adhesion of the coat to the substrate. It depends on the quality of surface preparing methods, but very often even the plasma etching may skip the places where the quality of the
TABLE 1: Main parameters of the EpoxyPAN coating material.

\begin{tabular}{lc}
\hline Parameter & Meaning \\
\hline Pressure strength [MPa], no less & $60-75$ \\
Adhesion [MPa], no less (maximum) & $3.5-(15)$ \\
Mass density [g/cm ${ }^{3}$ ], no more & $1.3-1.8$ \\
Water absorption [\%], no more & $1-1.5$ \\
Water tightness, W [MPa], no less & W18- \\
Coating thickness [mm] & W20 \\
[pH] water, mean value, for long-term use & $0.4-5.0$ \\
Frost resistance, no less [cycles] & $1.5-3.0$ \\
Relative lengthening, no less [\%] & 600 \\
Maximal angle of bending [ ${ }^{\circ}$ ], no less & 0.5 \\
Wear and tear mass losing [g/cm ${ }^{2}$ ], no more & 35 \\
Temperature proof [ ${ }^{\circ} \mathrm{C}$ ], no less & 0.1 \\
Flammability class, no more & 160 \\
Class of toxicity of combustion products, no more & $\Gamma 1$ \\
Self-firing & $\mathrm{T} 1$ \\
Spreading of the fire & no \\
Lifetime [year] & no \\
\hline
\end{tabular}

substrate surface is not on the required level. To improve this situation we decided to use the giant resonance increasing interaction forces between the tor-like nonmetallic particles with the external electromagnetic waves [15]. Astralenes are exactly the tor-like carbon particles and their disperse interaction with the surface of the substrate and polymer matrix leads to self-condensation on the interphase boards between the substrate and coating and to self-condensation on the interphase boards between the polymer matrix and disperse fillers, if the polymer is filled by some high module fillers [16].

If the polymer matrix of the composite is epoxy polymer and if the fillers have included into it are the short and thin microfibres with astralenes on its surface, such composite has to be named "EpoxyPAN" (Epoxy Polydisperse Armed Nanocomposite). In most cases we have taken the disperse quartz and dispersed silicon carbide as fillers in EpoxyPAN compositions. Additionally to grate value of the adhesion, it was received the best waterproof property of this composite coating and the best level of the wear and tear resistance, no more than $0.1 \mathrm{~g} / \mathrm{cm}^{2}$ mass losing (Table 1 ).

The EpoxyPAN coating can provide almost absolute water protection to the walls of buildings, so the heat transfer coefficient will be unchanged at any weather.

Now there are several objects with EpoxyPAN coating, which are serving for more than 5 years (Figure 1).

Application of the EpoxyPAN coating may be useful not only for the water isolation of the house constructions, but also for the increasing of the load-carrying ability of construction elements.

For example, the wood beam $100 \times 100 \mathrm{~mm}$, coated by EpoxyPAN for the bending test, was broken, but after decreasing the pressure the beam returned back to the previous 


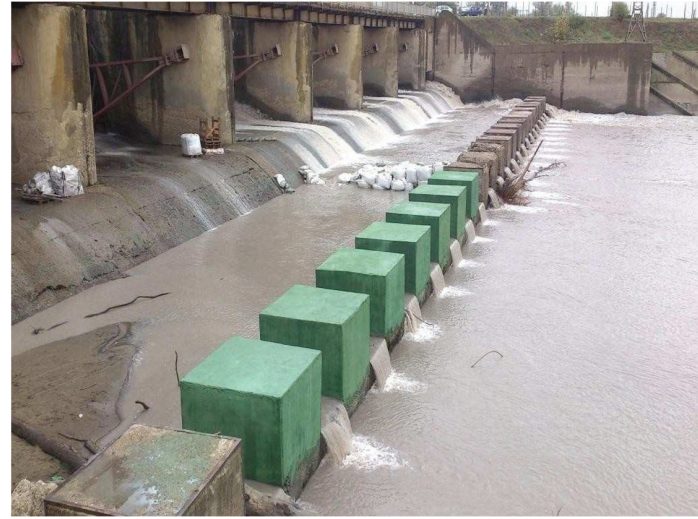

FIGURE 1: The ice-protection devices of the Belorechinskaya dam have been coated by the EpoxyPAN after 3 years of exploitation (green color).

form. This phenomenon means that the EpoxyPAN coating is possible to increase the "ductility" of the civil construction elements. This property gives to people an additional chance to survive if the earthquake suddenly happens. All the results fixed in Table 1 were received by testing the EpoxyPAN by the standard methodics.

\subsection{A New Knowledge about the Electromagnetic Waves} Absorption Spectra of the Carbon Nanoclusters and Its Application for the "Clever" House. The knowledge about the optical properties of carbon nanoclusters of different kinds, especially in $\mathrm{THz}$ diapason of frequency $[17,18]$, was not so spacious and publication on these topics was rather rare. Only in 2012-2013 years the comparative absorption spectra of the several different types of carbon nanoclusters (Fullerenes C-60 and C-70, carbon multiwall nanotubes gas phase produced, carbon multiwall nanotubes arc produced, astralenes, disperse shungite, colloidal graphite, and carbon nanoporous microfiber) at the frequency range $0.06-3 \mathrm{THz}$ have been researched $[19,20]$.

Astralenes and carbon nanoporous microfibers (CNPMF) were manufactured at STC of Applied Nanotechnologies. Colloidal graphite and multiwalled carbon nanotubes made by the gas-phase technology were provided by Professor L. N. Patrikeev (MEPHU, Moscow). For manufacturing the samples with different concentration of nanocarbon particles suitable for the study of the $\mathrm{THz}$ spectra in the $60 \mathrm{GHz}-3 \mathrm{THz}$ frequency range the host medium with low absorption and convenient to obtain samples with required shape was necessary. We used the mixtures of the polyethylene powder with the nanocarbon particles pressed in the mold. All the measuring has been done on the Teraview TPS Spectra 3000 system time-domain spectrometer by Ph.D. Irina Khromova, Assistant Professor, King College London.

It was founded that these spectra differ one from another significantly. In particular, it concerns the absorption coefficient dependence from the concentration of the nanocarbon clusters in the frequency range $0.06-1.5 \mathrm{THz}$. Most part of the researched nanocarbon clusters showed the good agreement with the Lambert-Beer law. In these cases the dependence

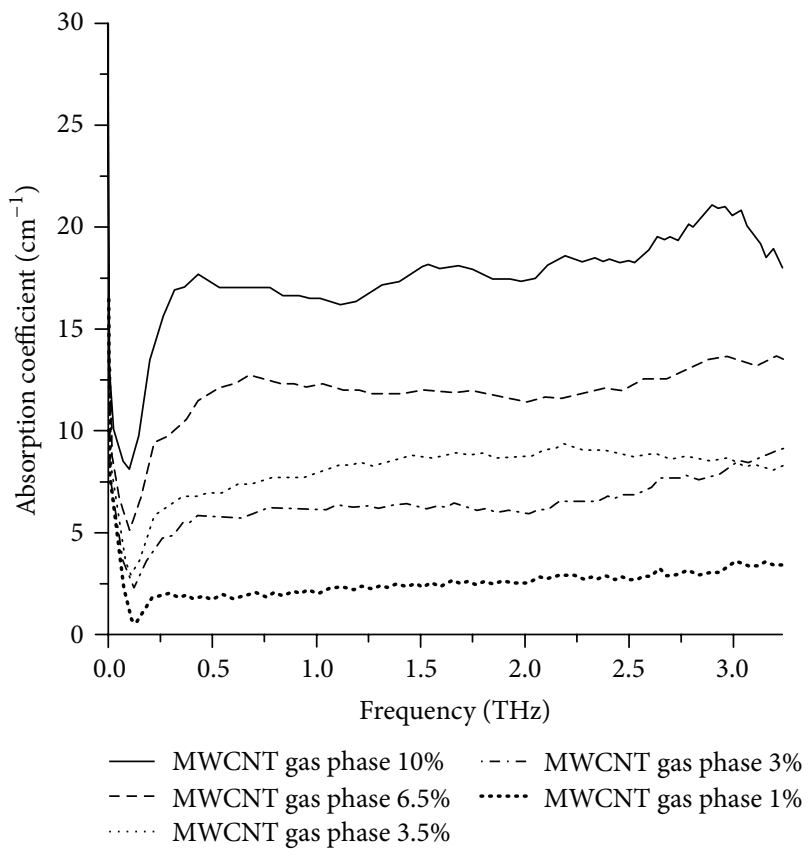

FIGURE 2: Carbon multilayer nanotubes (gas-phase technology made) absorption spectra changes with the increasing of their concentration in a plastic bag, $\%$ mass.

of the absorption coefficient from the concentration was linear (Figure 2). Only astralenes and carbon nanoporous microfiber have demonstrated strong nonlinearity of their electromagnetic waves sorption dependence (Figures 3 and 4). Beginning from the concentration in $4-7 \%$ mass, the absorption coefficient increases rapidly, especially in the low-frequency part of frequency range. It means that it is possible to join both types of nanoparticles in order to receive the universal sorption material for wide frequency range. These fillers can be added to the different building materials, especially to the heat-insulating layers, to provide the electromagnetic waves protection inside the house.

All electronic devices, used for the monitoring of the status of the buildings, require electric power supply and depend on the external condition during its exploitation. To avoid any negative influence, caused by changes in external parameters, it is necessary to use special electronic cooler.

However, a method to provide the continuous monitoring of the strained state of the framing of the building without any electric devices was developed. It is enough to include the optical devices, made of the metamaterials, sensitive to the pressure, deformations, or the temperature changing, into the most important constructive parts of the house.

The asymmetrical hyperbolic media can be preformed of such materials [21], which may be potentially used in high effective photovoltaic devices. Possibility of changing of the optical properties in a wide range is the most important property of the metamaterials. It is especially important if these changes take place in transparent atmosphere [22].

For the comparing, the dependence of the permittivity of the pure epoxy polymer without any filler from the temperature is shown in Figure 6. For the pure epoxy polymer, the 


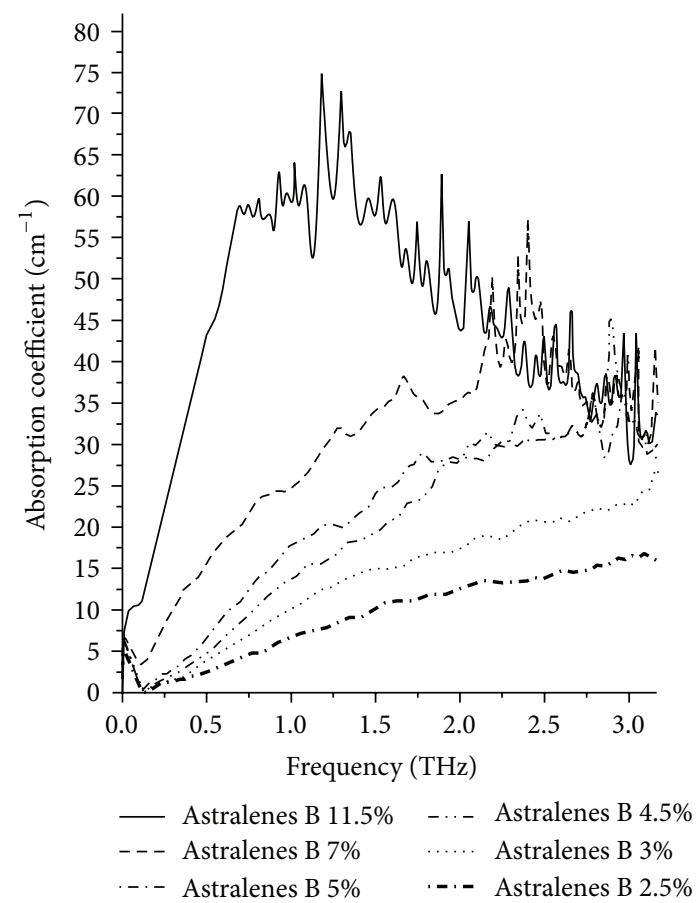

FIGURE 3: Astralenes absorption spectra changes with the increasing of their concentration in a plastic bag, \% mass.

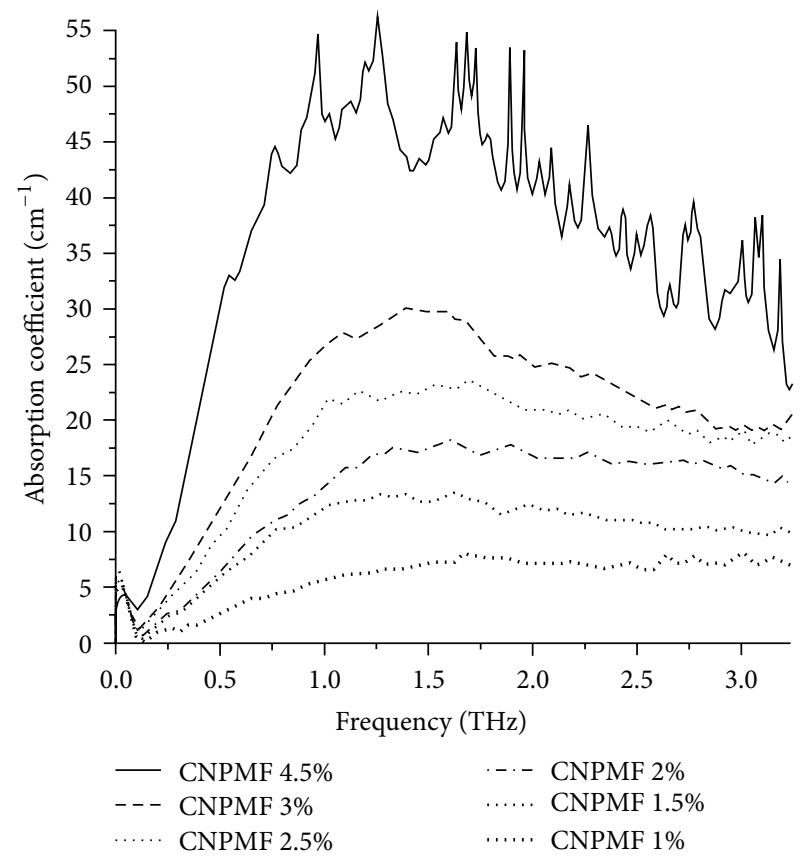

Figure 4: Carbon nanoporous microfibers absorption spectra changes with the increasing of their concentration in a plastic bag, $\%$ mass.

permittivity increased strongly with the temperature growth in the low-frequency diapason. For the doped epoxy polymer, at the temperature range $70^{\circ} \mathrm{C}-200^{\circ} \mathrm{C}$ the permittivity for the frequency diapason 105-108 $\mathrm{Hz}$ begins to decrease (Figure 5). These measurements have been done into the Resource Centre of the SPbGU.

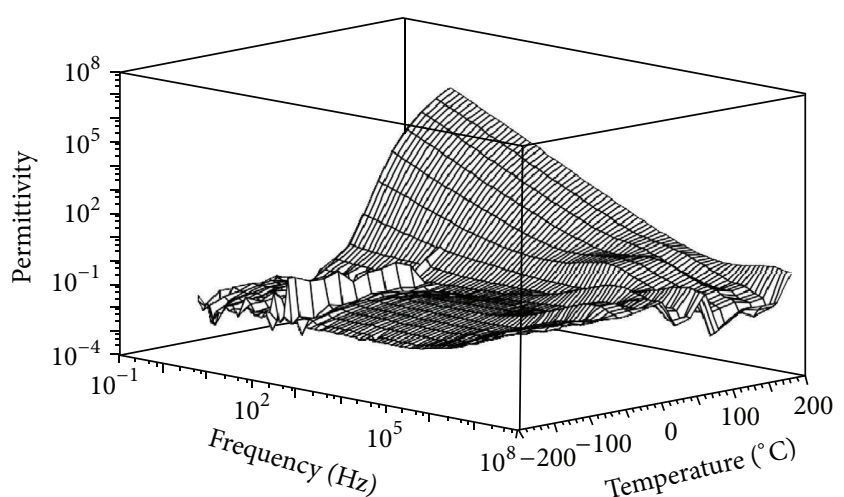

FIGURE 5: Dependence of the permittivity of the epoxy polymer with carbon nanoporous microfiber (3\% mass) from the temperature at the frequency range $1 \mathrm{~Hz}-0.1 \mathrm{GHz}$.

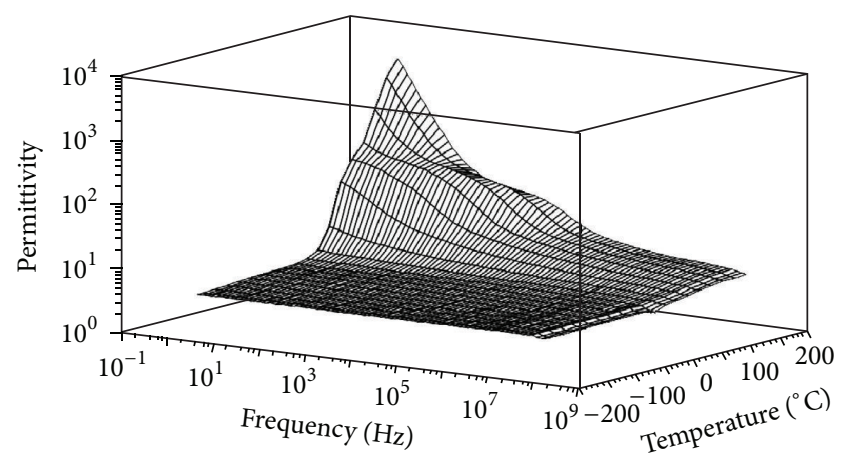

FIGURE 6: Dependence of the permittivity of the epoxy polymer without any filler from the temperature in the frequency range $1 \mathrm{~Hz}-$ $1 \mathrm{GHz}$.

It means that in this temperature diapason the permittivity and index of the refraction become negative. This is a useful property of metamaterial.

It is rather easy to include a piece of such polymer composite into the house construction parts and examine it by external light source or even by eyes (the color of the surface of this sensor will change with high level of heating, e.g., or with high level of strain state). And this type of house monitoring systems will not depend on external electric power source.

Another possibility for improving house safety is to use astralenes doped carbon plastic for the lightning protection [23]. Nonlinear electric conductivity of the astralenes doped carbon plastic is possible to provide protection from electric discharges during the thunderstorm.

\section{Conclusions}

New kinds of the nanocomposite materials based on the application of the astralenes (tor-like carbon nanoparticles fulleroid type) and carbon nanoporous microfiber are possible to provide higher level of the safety and comfort in living area of the building:

(i) New type of protective coatings, EpoxyPAN, provides high level of moisture insulating in houses and 
increases the strength of constructions; wood details become "ductile" and restore their form after being broken.

(ii) New knowledge about the interaction of the high frequency electromagnetic waves and nanocarbon clusters provides the possibility of developing the nanocarbon clusters mix that would make available sorption of the electromagnetic waves in a wide range of frequencies and provide the electromagnetic waves protection inside the houses.

(iii) The epoxy polymers have been doped by the carbon nanoporous microfiber which becomes the metamaterial at the temperature range $70^{\circ} \mathrm{C}-200^{\circ} \mathrm{C}$ and can be applied as a base for developing the energy independent sensors for monitoring the state of the building parts, especially at extreme conditions.

All these new solutions and methods became possible due to the particular properties of the new kinds of the nanocarbon clusters, astralenes and carbon nanoporous microfiber.

\section{Competing Interests}

The authors declare that there is no conflict of interests regarding the publication of this paper.

\section{References}

[1] A. N. Ponomarev and M. E. Yudovitch, "Carbon nanoparticles fulleroid type tor-like form," US Patent no. 2397950, 2008.

[2] A. N. Ponomarev, M. E. Yudovitch, and A. A. Kozeev, "The sulphoadduct of the carbon nanoclusters and the technology of its production,” RU Patent no. 2478117, 2010 (Russian).

[3] A. N. Ponomarev, "Carbon nonporous microfiber," RU Patent no. 2570794, 2014.

[4] A. I. Shames, E. A. Katz, A. M. Panich et al., "Structural and magnetic resonance study of astralen nanoparticles," Diamond and Related Materials, vol. 18, no. 2-3, pp. 505-510, 2009.

[5] A. N. Ponomarev, M. N. Vauchsky, V. A. Nikitin et al., "Composition for building materials," RU Patent no. 2233254, 2000.

[6] A. N. Ponomarev, "High quality concrete. Analyze of possibilities and practice of appliance of nanotechnology methods," Magazine of Civil Engineering, vol. 6, pp. 25-33, 2009 (Russian).

[7] E. V. Kishinevskaya, N. I. Vatin, and V. D. Kuznetsov, "Perspectives of appliance of nanoconcrete in monolithic large span ribbed spans with post-tensioning," Magazine of Civil Engineering, vol. 2, pp. 54-58, 2009 (Russian).

[8] A. Ponomarev, M. Knezević, N. Vatin, S. Kiski, and I. Ageev, "Nanosize scale additives mix influence on the properties of the high performance concretes," Journal of Applied Engineering Science, vol. 12, no. 3, pp. 227-232, 2014.

[9] A. N. Ponomarev, V. D. Gus'kov, V. V. Vorontsov et al., "Advanced composite neutron-absorbing materials for containers of dry storage of nuclear waste for nuclear plants under construction," Magazine of Civil Engineering, vol. 9, no. 35, pp. 9-13, 2012 (Russian).

[10] S. S. Kiski, I. V. Ageev, A. N. Ponomarev, A. A. Kozeev, and M. E. Yudovich, "Research of the possibilities of modifying the carboxylate plasticizers as part of modified fine grained concrete mixtures," Magazine of Civil Engineering, vol. 8, no. 34, pp. 42-46, 2012 (Russian).

[11] M. Klyachko, "The development of GIS, EQ-DISC and DIMAK as the best tools for seismic risk analysis on the urban areas," in Proceedings of the 5th International Conference on Seismic Zonation, vol. 1, pp. 158-166, Nitsa, France, 1995.

[12] M. Klyachko, "Seismic risk and sustainable safety," in Proceedings of the 14th World Conference of Earthquake Engineering (WCEE '08), pp. 44-46, Beijing, China, 2008.

[13] A. A. Blagonravova, I. A. Pronina, and A. M. Tartakovsky, "Polyurethan saving varnish coating," Varnish Materials and Its Application, vol. 2, pp. 8-11, 1975.

[14] A. I. Reibman, Zashchitnye Lakokrasochnye Pokrytiya, Khimiya, St. Petersburg, Russia, 1978.

[15] A. N. Ponomarev, M. E. Judovich, M. V. Gruzdev, and V. M. Judovich, "Interaction of electric field with nonmetallic nanoparticles. Part I. Theoretical estimation of topological factor," Nano- and Microsystem Technics, vol. 6, pp. 45-51, 2009.

[16] A. N. Ponomarev and O. L. Figovsky, "The giant resonances at disperse interaction of non-metallic particles and examples of the composite materials modified by Astralenes," Scientifical Israel-Technological Advantages, vol. 3, pp. 54-57, 2010.

[17] S. Kumar, N. Kamaraju, B. Karthikeyan, M. Tondusson, E. Freysz, and A. K. Sood, "Terahertz spectroscopy of singlewalled carbon nanotubes in a polymer film: observation of lowfrequency phonons," Journal of Physical Chemistry C, vol. 114, no. 29, pp. 12446-12450, 2010.

[18] S. Adhikari and R. Chowdhury, "Vibration spectra of fullerene family," Physics Letters A, vol. 375, no. 22, pp. 2166-2170, 2011.

[19] I. Khromova, L. Melnikov, and A. Ponomarev, THz Absorption in Carbon Micro- and Nanoparticles, 2013.

[20] I. Khromova, L. Melnikov, and A. Ponomarev, “THz properties of carbon nanostructures," in Proceedings of the International Conference on Coherent and Nonlinear Optics, p. 554, 2013.

[21] I. S. Nefedov, L. A. Melnikov, and E. I. Nefedov, "Asymmetrical hyperbolic media and their potential applications in photovoltaics and photonics," in Metamaterials VIII, vol. 8771 of Proceedings of SPIE, p. 179, Prague, Czech Republic, 2013.

[22] Y. Yang, A. Shutler, and D. Grischkowsky, "Measurement of the transmission of the atmosphere from 0.2 to 2 THz," Optics Express, vol. 19, no. 9, pp. 8830-8838, 2011.

[23] E. N. Kablov, O. A. Komarova, S. I. Ilchenko et al., "Composite lightning protection coating," RU Patent no. 2217320, 2002 (Russian). 


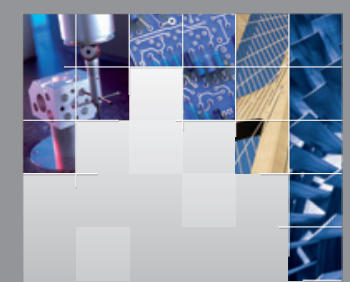

\section{Enfincering}
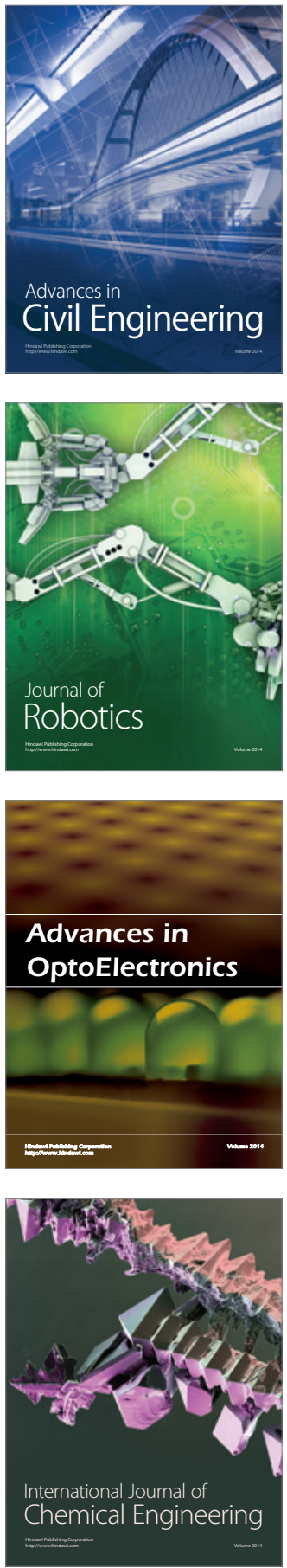

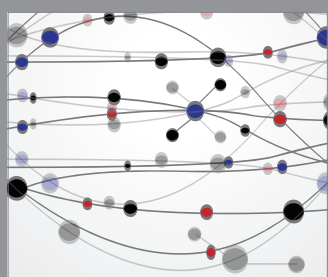

The Scientific World Journal

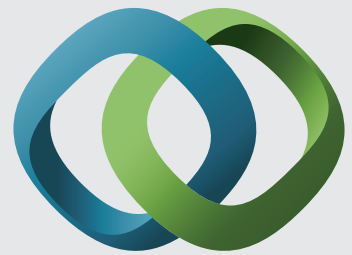

\section{Hindawi}

Submit your manuscripts at

http://www.hindawi.com
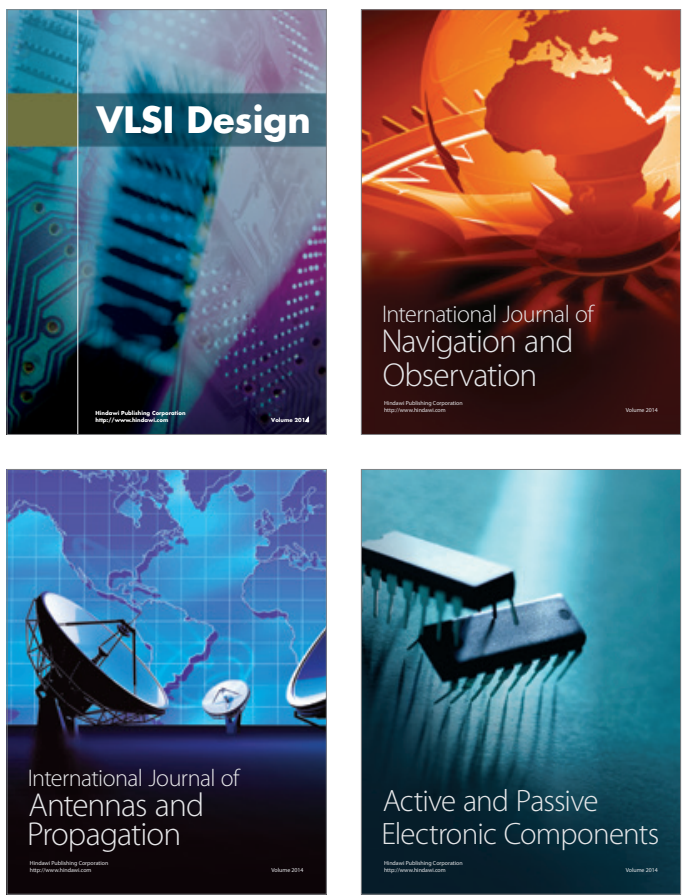
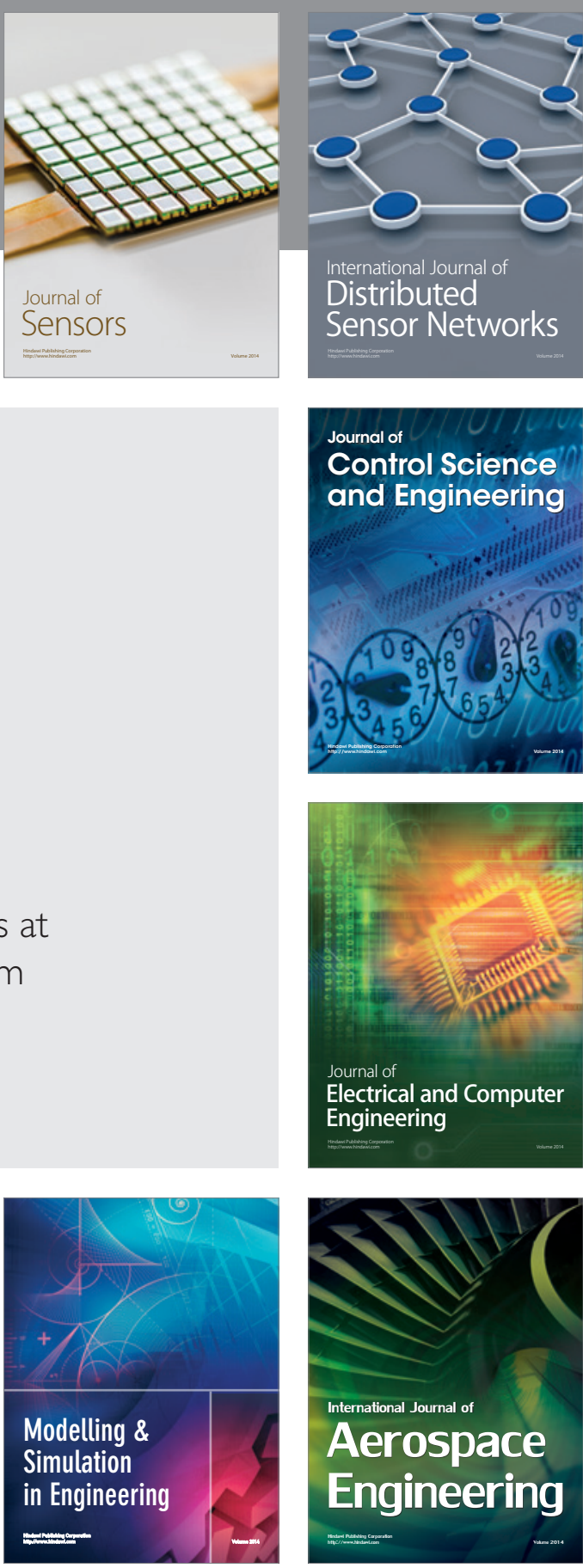

International Journal of

Distributed

Sensor Networks

Journal of

Control Science

and Engineering
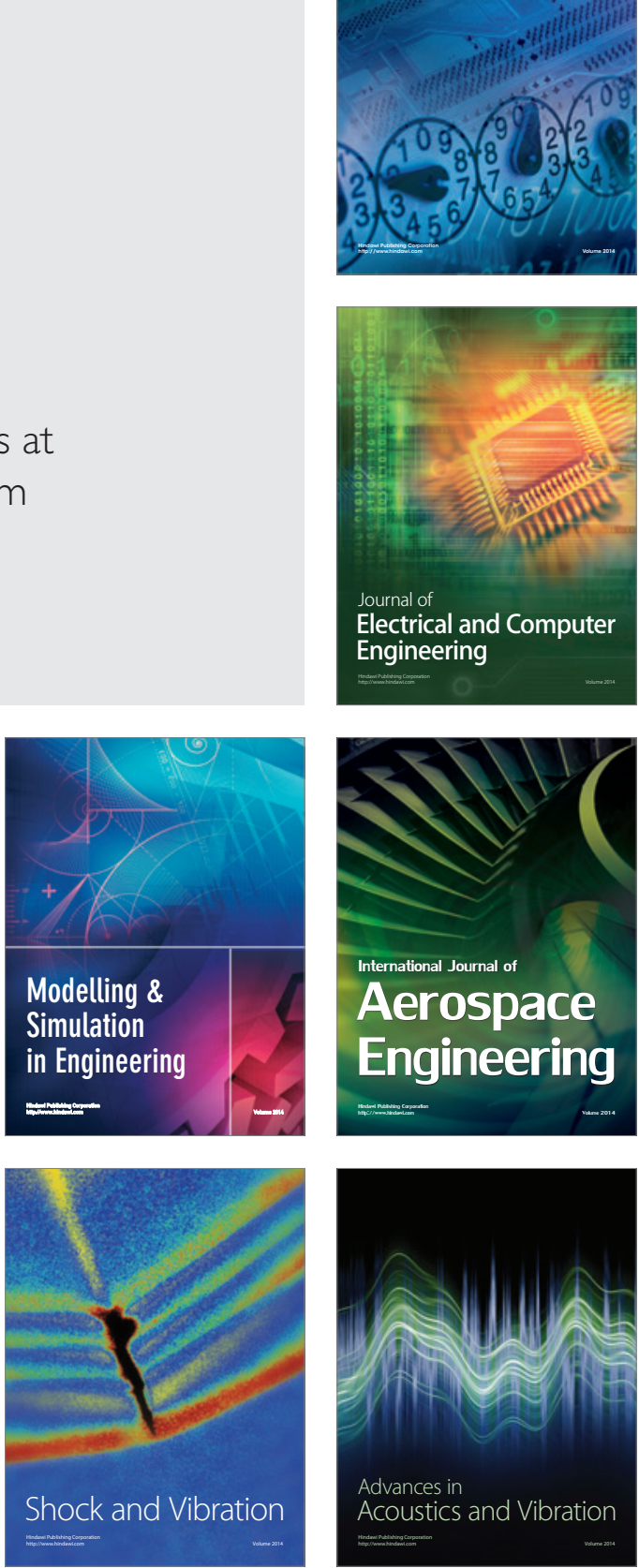